\title{
Discussion on
}

\section{"The place of traffic engineering in the Institution"}

The President said that there were four important questions to which answers were urgently needed.

(i) Is any special provision by the Institution needed to cover the subject of traffic engineering?

(ii) To what extent is it advisable to make any such provision open to active participation by non-members of the Institution?

(iii) Should the practical training of traffic engineers include a period on works construction or should practical experience of traffic engineering be sufficient in itself? In other words, should practical experience of traffic engineering be recognized as the equivalent of practical training on works as one of the basic qualifications for Corporate Membership of the Institution?

(iv) If the foregoing, or any of them, are accepted, should a special Committee, drawn from experts in the field (including if desired non-members of the Institution, as with Soil Mechanics), be set up to organize and run its activities?

Dr W. H. Glanville (Director of Road Research, Department of Scientific and Industrial Research), introducing the subject, said that no definition of traffic engineering had been given in the notice convening the meeting, so he proposed to read the definition adopted by the Institute of Traffic Engineers in the United States:-

"Traffic engineering is that phase of engineering which deals with the planning and geometric design of streets, highways and abutting lands and with traffic operation therein, as their use is related to safe, convenient and economic transportation of persons and goods."

That might sound involved, but what it meant was that anything to do with providing for and controlling traffic was of interest to the traffic engineer. His contribution was towards the efficient, orderly, convenient, and safe traffic conditions, including the problem of parking. To do the job properly he must collect and analyse facts about traffic. He needed to know how the needs were to be satisfied by the various devices and designs which were available to him; he was not concerned, however, with structural design, with whether or not a bridge was strong enough, or with whether it should be a suspension bridge or of some other type. He was concerned with the width of the bridge, the number of lanes, the width of the lanes, the design of the approaches, and such things as lighting and the non-skidding properties of the surface. He was also interested, before the bridge was built, in its proper location to satisfy traffic demands. For that reason he was interested in traffic studies of origin and destination and so on, which were made beforehand, as well as in the economic studies which might be associated with them. In a wider sense he was also interested in the broad planning of the whole system of roads to satisfy the demand.

3. There was obviously a big field of interest for the traffic engineer, quite apart from the structural side; and, with the enormous growth of traffic which had taken place in recent years, there could be no doubt about the importance of the subject of traffic engineering. Those who were concerned with it knew also that there was no doubt about the demand for people who were competent to work in this field. The shortage of such people was acute. The universities were doing something, and it was to be hoped that they would do more, to train traffic engineers, and the Road Research Laboratory was running training courses.

4. Dealing briefly with the four questions which the President had read out, Dr Glanville said that in reply to the first it was necessary to consider whether the present 
Road Division of the Institution, as it stood, provided sufficient opportunity for those interested and occupied in traffic engineering to meet and discuss their problems, or if traffic engineers dealt with a subject which was sufficiently an entity in itself to warrant a special division or group or section, within or under the cover of the Institution. The Divisions up to now had been largely concerned, particularly in recent years, with selecting Papers, and had been restricted in their activities, but there was no reason why those activities should not be widened as much as was necessary. It would be desirable to take into consideration also, however, the example of the British Section of the International Society of Soil Mechanics and Foundation Engineering, which was serviced by the Institution, which also ran its Journal. The British Section of that Society provided a forum for a group of professional enthusiasts to meet and discuss their problems. Not all of them were corporate members of the Institution, and in fact the present distinguished Chairman was not a corporate member of the Institution. The question arose of whether or not something of that kind would meet the needs of traffic engineering.

5. It was also necessary under this heading to consider whether or not any special diploma in traffic engineering should be awarded by the Institution. That had not so far been done in any feld, but it was not, of course, ruled out.

6. The second question was to what extent it was advisable that any provision made for traffic engineers should be open to active participation by non-members of the Institution. It was a fact which must be frankly admitted that many of the leading experts in traffic engineering were not engineers by training. Some of his colleagues at the Road Research Laboratory belonged to this group, and if they and similar people were excluded from anything which was provided he was sure that all sides would suffer, as soil mechanics would have suffered in such circumstances. It seemed to him that nothing would be lost and much would be gained by ensuring that all the experts in the traffic-engineering field joined together to make what was done a success.

7. The third question was whether or not traffic engineering, or rather practical experience of it, should be recognized as the equivalent of practical training on works as one of the basic qualifications for corporate membership of the Institution. There was, of course, no question of dispensing with Sections A and B, but should the man who was going to make his career in traffic engineering be permitted to count his practical experience in traffic engineering as his works experience? All engineers had to specialize in one way or another and could have only a limited practical experience fitting them for a restricted field of engineering activity. There might be little advantage, if a man was going to make a career in traffic engineering, in his having much practical experience in fields other than his own. It would be useful if he could, but the question of whether it was of advantage or not was another matter, because he had to spend the years in one way or another, and would they be better spent in getting practical experience in his own field? That was a subject which must be considered.

8. The fourth question dealt with the setting up of a special committee of experts, perhaps including some who were not members of the Institution, to consider this matter and presumably make recommendations to the Council.

9. Those were the questions, and Dr Glanville hoped that they would be discussed from the point of view of how best to provide for the technical needs of the traffic engineer and ensure that he was a really efficient person and had full opportunity to discuss his problems. Dr Glanville did not think that the meeting should be concerned with exactly where traffic engineering lay with respect to other engineering fields. The question was rather how to cater properly for the needs of the traffic engineer and how best to help in the development and use of traffic engineering as an applied science.

\section{Discussion}

Sir Herbert Manzoni (City Engineer, Birmingham) said it was important to decide what was considered to be the province of traffic engineering. He thought that the term "traffic engineering" was a misnomer; it should be "highway traffic engineering", 
because the railways and even the waterways organizations had to use a somewhat similar technique.

11. It seemed to him that traffic engineering really dealt with the use factors which were basic to the design of highway systems. It was so much a part of highway engineering that it was very dangerous to attempt to divorce it from highway engineering. He had read some of the American books, and particularly a recent very good one, on traffic engineering, and it seemed to him quite obvious that there were two sides to it. There was the side which could be dealt with by someone who was not an engineer at all, but who might be an informed policeman or a surveyor, and there was the other side, which could be dealt with, in his opinion, only by those whose training lay in that department of civil engineering which was referred to as highway engineering. Traffic surveys were necessary, and the analysis of those surveys, the consideration of methods for the control of traffic, and so on. Those things could be done just as well by someone who had had no engineering training at all as by an engineer, but that was not the whole of what was usually understood as traffic engineering.

12. The traffic engineer, as Dr Glanville's American definition showed, had also to consider the width of highways, the form of junctions where traffic had to weave, and possibly the siting of highways. Sir Herbert claimed that that could not be done adequately except by someone who had a sufficient knowledge of structural engineering to be able to decide the economics of a scheme on one site as against a scheme on another. The one might be in cutting and the other on viaduct. The design of a junction might well involve considerations of a structural nature if it was to be built at the cheapest price and in the best way. This made it essential that the traffic engineer should have a knowledge of highway engineering, or rather of the structural engineering which was involved in highway engineering.

13. Sir Herbert had spoken to Dr Kolbuszewski, who was in charge of the School of Highway Engineering in Birmingham, after his return from Rio de Janeiro, where there had been a conference on these matters, and Dr Kolbuszewski had told him that the Americans there had shown an increasing recognition of the fact that the subject of traffic engineering could not be divorced from highway engineering, and some of them had placed considerable insistence on this. Sir Herbert submitted that every effort should be made by the Institution to see that there was no divorce. To his mind, traffic engineering in its relation to highway engineering was like the relation of hydraulics to water engineering. It dealt with the flow of traffic and had to take into consideration the flow resistances which were set up by different forms of highway. It had to consider factors which impinged on the structural design of a highway system.

14. He said that traffic engineering also could be applied, to a system of existing streets without any alteration whatever to those streets. He knew that to his cost, because more than 20 years ago he had been responsible for putting in a one-way traffic scheme in Birmingham; it had suffered many jocular references, but in fact it had been a scientific scheme, which had worked in 1935 and was still working today, despite the increase of traffic. It would go on working, because it had been so designed that the flow of traffic along the streets was calculated according to the capacities of the streets; the same was true of the junctions, and it was not possible to get any more traffic in than the streets were designed to take.

15. Another example of traffic engineering applied to existing streets was Trafalgar Square, where there was a method of control by traffic lights which allowed a certain flow of traffic round the square, into it, and out of it. That was traffic engineering, but it was a side of traffic engineering which could be dealt with by someone who was not a civil engineer. That was not the whole of traffic engineering, however, and when it was necessary to apply traffic engineering to new works, he maintained that a properly trained civil engineer who had specialized on highways was the best man, if not the only man, to make the right decisions.

16. Relating that introduction to the questions before the meeting, he would say in reply to the first question that this was a matter for serious consideration of the functions and scope of the Road Division. He thought that they must expand their 
activities so that there could be no doubt in the mind of anyone that they covered adequately the subject of traffic engineering.

17. With regard to the second question, whether or not non-members of the Institution should be allowed into these deliberations and discussions, he would say that they should not, except on special occasions when Papers were being read and it would be worth while to invite representatives of the police and of transport organizations to hear the Papers, and even to take part in the discussions if that were thought to be advisable.

18. With regard to the third question, there was definite need for the Institution to do a little more to recognize the practical applications of engineering science to specific subjects than was being done at present. The only recognition which the Institution now gave in its examinations to practical engineering was in the professional interview. There was very probably a need for some form of examination in several of the special applications of civil engineering. He had in mind water supply, highways, and other specific applications of that nature, which at present had no place in the examinations, apart from the professional interview.

19. After what he had said in reply to the first three questions, his answer to the fourth would be obvious. He thought that this was essentially a matter for the Road Division to discuss with a view to enlarging their activities and bringing forward a scheme for including a proper recognition of this very important subject in the normal activities of the Institution.

Mr Joseph Rawlinson (Chief Engineer, London County Council) said that the answer to the first was "yes". Before 1956, road construction in Britain had never been taken very seriously by successive Governments. The result had been that only a few engineers had interested themselves in traffic engineering. Today, he was glad to say, the Government had given a fairly clear indication that they were in favour of a long-term programme of road schemes, the cost of which might be of the order of $\mathfrak{f 6 0}$ million a year for the whole country. The need existed, therefore, for skilled and properly qualified traffic engineers, and so there was a clear responsibility on the Institution to cover the subject of traffic engineering, which was a branch of civil engineering.

21. The Institution should, in his view, grant a diploma by examination in traffic engineering, and this should be an additional qualification to normal associate membership. It would, in his view, not be sufficient to add an additional subject to the ordinary examination, because local authorities-and they were to a large extent those who were most interested-were unlikely to look upon that as a special qualification. In the medical profession, the D.P.H. was a special qualification for doctors who specialized in public health work. If the Institution failed to grant a special qualification for traffic engineering, other institutions and associations would do so.

22. Turning to the second question, he thought that the Institution must exercise the greatest care in admitting non-members to membership solely because of their contribution to or interest or skill in traffic engineering. At the same time, he was conscious of the fact that there might be a number of people such as professors and lecturers at universities and technical colleges, together with a number of scientists, who on their merits would be entitled to membership; but care should be exercised in their selection.

23. On the third question, subject to what he had said in reply to the second question he believed that traffic engineers should serve a suitable period on works construction. Traffic engineering, including geometric design, required a different application in heavily-built-up areas from that which it required in wide open spaces. In London it was safe to say that in the design of road junctions important factors other than those of purely traffic engineering intruded into the general picture. Layouts had usually to be seriously amended not because of design difficulties but because of the tremendous expense of acquiring the necessary property, and to meet other difficulties. This usually resulted in having to arrive at a compromise with other interested parties, and a satisfactory 
solution could be achieved only if the engineer had a good knowledge of all the problems affecting the improvement-not only traffic engineering. It was possible for a traffic engineer to be good at his job without this additional experience, but Mr Rawlinson was quite sure that a man would be a better traffic engineer with this experience.

24. With regard to the fourth question, he believed it would be wise to set up a committee to advise the Council how best to institute an examination for this important branch of civil engineering, but not in the first place to run its activities. With regard to the composition of this committee, he thought that if there were any outstanding traffic engineers in the country who were not members of the Institution, then if they so wished, and if the Council were satisfied, they should be made corporate members, which would qualify them to take a full and active part in the affairs of the Institution. The position could be reviewed every two years.

Mr W. F. Adams (Ministry of Transport and Civil Aviation), did not agree entirely with Sir Herbert's description of those parts of traffic engineering which did not require an engineer to deal with them. In that connexion, Trafalgar Square had been a particularly unfortunate example to give, because that had called for a good deal of knowledge of traffic science and traffic handling.

26. It was now a little more than 30 years since $\mathrm{Mr}$ Adams had first been engaged on traffic engineering, and of that time 16 years had been spent wholly on traffic engineering. He felt that that was too big a proportion. Traffic engineering was not, and should not be, a career in itself; in his opinion, it should be more of an episode in the career of a civil engineer. It was true that there was need for a few specialists, and they might make a career in the subject, but in general the highway engineer should contemplate specializing in traffic engineering for a time and then, with that experience behind him, returning to more general aspects of highway engineering. One of his colleagues had said that what was important was traffic engineering rather than traffic engineers, and the more widely traffic engineering knowledge was spread amongst highway engineers the better.

27. He thought that more provision by the Institution was necessary. Whether it should be special or not was another matter; but, unless the Road Division could arrange for more discussions on traffic engineering matters, and more Papers on the subject could be obtained, it would be desirable to arrange for something outside the Road Division.

28. From his previous remarks it would be realized that he was not in favour of a diploma. Traffic engineering should be part of the equipment of all highway engineers.

29. On the extent to which it was desirable to make provision for non-members of the Institution to participate, he thought that the discussions would lose something if they did not have the help of scientists, statisticians (if he might distinguish them from scientists), planners, and the police. If it were agreed to admit them to meetings of the kind in question it would be necessary to be selective in their standards regarding the people to be admitted, or to have a clear definition of what the scope of the discussions and activities of such meetings was to be. That was particularly important in order that the discussions should be objective and not serve as a sounding board for the partisan views of interested organizations. Those who had anything to do with the meetings of local road-safety committees would know what he meant.

30. With regard to the practical training of traffic engineers, in his view practical experience of traffic engineering should be accepted as part-not the whole-of the qualification for associate membership. A traffic engineer would be a better traffic engineer for knowing something about what his proposals were likely to cost and how they were to be carried out, and in particular what interference with traffic was likely to be caused while they were being carried out.

31. Whether or not a special committee was required must depend very much on the answer to the first question, i.e. on whether the Road Division could do more to promote the discussion of highway engineering subjects. 
Mr Stanley Mehew (County Surveyor, Derbyshire) considered that traffic engineering was fundamental to nearly all the highway planning and design problems on which highway engineers spent so much time and though it was not a new subject it was one to which much more specialized attention could be devoted with great value to all concerned. There was a good deal of leeway to make up and he had no doubt that special provision by the Institution was needed to cover the subject.

33. It was more difficult to decide on the best approach but he agreed completely with Sir Herbert Manzoni that traffic engineering should not be divorced from highway engineering of which it was a part. He hoped that it could be treated by, or in very close association with, the Road Division of the Institution and in a manner which would give the traffic engineering aspect every opportunity to develop rapidly.

34. Ho favoured a type of organization which would enable participation as appropriate from time to time by anyone having a useful contribution to the subject irrespective of membership.

35. On the third question he felt, like Mr Adams, that the practical training of traffic engineers should include a period on works construction. Basic engineering experience was implicit in the proper use of the technique of highway traffic engineering and Dr Glanville, in his explanation of the definition adopted in America, had brought that point out clearly. For qualification purposes; traffic engineering should not be accepted as the sole experience necessary. He agreed with $\mathrm{Mr}$ Rawlinson about the merits of a diploma which would make it clear that there had been some measure of specialization on the subject, but not to the exclusion of highway engineering as a whole.

36. The setting up of a special committee with a limited life would help to start the organization and to bring all aspects of it into focus. He thought that non-members of the Institution might well be associated with the Committee.

Mr C. I. P. Andren (University College, London) also replied affirmatively to the first question, because he believed very strongly that the Institution should formally acknowledge the fact that traffic engineering studies were an essential part of the work of the civil engineer. He also thought that it was not merely the highway engineer who should be directly concerned in any efforts which were made to encourage the use of traffic engineering techniques.

38. Without checking up on an official list, he had noted down the Papers which seemed to him to come within the field of traffic engineering, and had found that from 1945 onwards there had been more than twenty Papers on aspects of highway engineering coming at least partly within the usual definitions of traffic engineering and dealing with such subjects as traffic surveys, flow, capacity, delays, intersection layout, and so on. In the same period, there had been Papers in other Divisions of the Institution which in his opinion also came within the scope of traffic engineering. For instance, there were Papers which reported on the use of traffic-engineering measurement techniques, such as the recent Paper on the geometric design of airports ${ }^{1}$ and two Papers in the Railway Division, one on the design of large passenger stations ${ }^{2}$ and the other on the Victoria Line3. Both dealt in a very practical manner with pedestrian flow measurements and were of direct use to road engineers concerned with design from the traffic point of view. It would be a great mistake to leave the development of the subject of traffic engineering entirely in the hands of the Road Division.

39. His first point, therefore, was that traffic engineering studies should not be considered only as road studies. They should be concerned with all forms of transport. This was particularly so in cities, where traffic problems were at their most complicated, and where traffic engineering was urgently needed to supply solutions. If the cities of Britain were to be retained in anything like their present form, it was impossible to ignore the use of rails as well as roads and the interplay which took place for passengers and freight between the various forms of transport. Traffic engineering principles applied to transport as a whole were needed to deal with the problem in cities.

40. His second point was that engineers in the field of traffic engineering needed all 
the help which they could get from non-members of the Institution who, by virtue of their job, had some specialist interest in traffic problems. There were many such people. Apart from other engineers, such as electrical engineers, there were police officials and scientists engaged in research, many of whom, unlike those at the Road Research Laboratory, were not usually professionally concerned with traffic problems. A few years ago there had been an extremely illuminating Paper ${ }^{4}$ on the theory of traffic flow given at the Royal Society, a very interesting continuation of Mr Adams's own pioneer work on the subject of road traffic. It was important not to miss that type of contribution by referring to traffic engineering as only a part of highway engineering and narrowing it to the field of engineers only.

41. On the question of practical training, the Institution could encourage the subject by adding to the schedule of practical engineering training. He would like to see included there, either under a new heading or at least under the heading of highways, such subjects as traffic analyses, volume and directional censuses and surveys, parking surveys, and so on, and, perhaps under another heading, traffic-control devices. He would hope that a candidate who had had practical experience in those subjects would be able to put them forward as ranking equally with those already in the schedule.

42. He did not think that it was a practical proposition to include traffic engineering as an optional subject in the Institution's examination syllabus as things stood at present, because it seemed to him doubtful that there was any subject now in the syllabus which could fairly be dropped by anyone who aspired to become a civil engineer. At the undergraduate stage in the universities there was not a great deal of scope for more than an introduction to a specialist subject such as traffic engineering, within the present length of a degree course; and most of the opportunities of combining academic and practical study of traffic engineering must come at the postgraduate stage. The Institution should, he thought, consider at least making a small start in this direction, possibly by introducing the subject of elementary statistics in the mathematics syllabus of the examination. He was thinking particularly of methods of checking the validity of conclusions drawn from numerical data-significance tests, and also of the design of experiments, for instance by using sampling techniques. That kind of thing would have the additional value of being of very practical use to a range of other civil engineering subjects, as well as to traffic engineering.

Dr R. J. Smeed (Deputy Director, Road Research Laboratory) said that the problems involved in handling large numbers of vehicles were great and the solution of those problems was not likely to be obtained without a great deal of discussion. A forum was needed where the problems could be considered.

44. He proposed to relate his comments to the questions posed in the note and would start with the first two questions. There could be no doubt, he thought, that provision was needed to cover the subject of traffic engineering. The only possible question was whether the Institution was the most appropriate body to provide it, since there could be no doubt that the police, the planners, the economists, and others all had an important part to play. However, he thought it must be agreed that the part played by the highway engineer was so preponderant that it was appropriate that the highway engineers should sponsor the discussions.

45. However, traffic engineering required the assistance of other skills besides those of highway engineers and the contributions of persons who were not highway engineers should be welcomed.

46. Finally, turning to the third question, he thought it must be agroed that 2 years spent on engineering works would be useful to a traffic engineer. So also would a 2-year course in expressing oneself in good English, an extensive training in mathematics, in physics, in statistics, in psychology, and many other subjects. But, unfortunately the traffic engineer would generally have to do without them. The question posed should not be: "Is works training useful" but "Is it essential" and the answer must be, he thought, that it was not essential, for it should bo remembered that 2 years spent on works training would reduce the working life of a traffic engineer by about 
$5 \%$, with no obvious gain unless, in his future career he turned to work other than traffic engineering. It could, he thought, reasonably be argued that the absence of such works training should disqualify a man from being appointed to the most senior highway posts such as County Surveyor or Municipal Engineer, but he could not see why the junior staffs of these senior officers should all have to undergo a works training. They were not all going to attain the most senior posts.

Mr W. M. Ogden (Ministry of Housing and Local Government) said that the problem of designing roads was not so difficult as that of getting them built.

48. There was a distinction between the traffic engineering problems of the open country and those of the town, and he would confine his remarks to the town, in which there was an intimate relation between land use and the road system. In practice he had not found it possible to separate traffic engineering from town planning. It was well known that the development plans, prepared under the Town and Country Planning Act, 1947, set out first, the proposed pattern of land use, including a statement about the intensity of use; secondly, a supporting road system together with other means of transport; and thirdly, a programme of development, worked out to meet the changing needs of the town in both land use and highway terms.

49. The planning objectives were to promote efficient land use, to bring about a convenient system of communications (of which roads were the major part), and to preserve and enhance the beauty of the town. It was important to look forward towards the 21st century, with new materials, new needs, and a new challenge. This was a formidable task. It could be undertaken only by a partnership of people with several different skills and interests.

50. There was no single solution to the traffic problems of a city. There were many ways in which road problems could be solved, in whole or part, and different methods of transport were interdependent. The traffic engineer had a fundamental part to play in town planning. He was concerned not only with what might be called the engineering job of preparing designs but, and much more, in Mr Ogden's experience, with the development of policies for town reconstruction. The measuring of traffic flows, of congestion of the parking space required, and of analysing accident rates, were basic skills which the traffic engineer must bring to the task of policy formation. For example, the towns of the future might well have pedestrian precincts, urban expressways, car parks provided at economic prices, and high buildings with ample space for traffic movement between them. The planning authority would exercise control of development and of land use so that land use and traffic movement hung together as dependent parts of the whole. The traffic engineer, coming in with the town planner, the economist, the builder, and the surveyor would be able to produce solutions to what at the moment appeared to be an insoluble problem-of getting about conveniently in a large city in the not too distant future.

51. Mr Ogden then turned to the four questions put by the President. He felt certain that there was a need for a body to apply itself to traffic engineering in addition to road engineering, and he would couple that with town planning, which was going to determine very largely whether or not the work of the traffic engineer in towns could be brought to fruition with proper speed and economy and in terms of civic design. He believed that non-engineers such as economists and estate surveyors were essential to the team. He could not make up his mind about the question of practical training, and he was not sure that the stage had yet been reached where it was possible to decide that experience in traffic engineering was a sufficient discipline to be part of the conditions for the award of membership of the Institution. On the last question, he thought that some sort of machinery was required to tackle the problems of traffic engineering on a broad front and probably in new ways.

Mr J. I. Whitehead (Assistant County Surveyor, Dorset), who said that he represented what one speaker had described as the wide open spaces, replied affirmatively to the first question. Mr Andren had reminded the meeting of the number of Papers 
relevant to traffic engineering which had been submitted to the Institution; and it had also occurred to $\mathrm{Mr}$ Whitehead that there were probably traffic engineers who would like to submit Papers but were deterred by the immense quantity of material already offered to the Institution and which had to be published.

53. On the second question, the participation of non-members could be covered to some extent, perhaps, by the class of Associate, but whether the membership in that class could be extended he was not sure. The answer might be to publish something in the nature of Géotechnique, a traffic-engineering journal which would be on sale as an alternative to the full Proceedings for Associates, because they would not want to take the full Proceedings and have to pick out the few items of traffic engineering of interest to them. If there was a traffic-engineering journal on sale, it would better serve their needs.

54. With regard to training, he did not think that traffic engineering experience by itself should be sufficient to qualify for associate membership. His reason for saying that was that in a county highway authority, where he thought most opportunity of employment for traffic engineers would lie, they liked to recruit the type of young engineer who thought that he was going to get to the top and who wanted to be a county surveyor or city engineer. Mr Whitehead did not think that traffic engineers would ever become chief officers in their own right, and did not think that they should do so. The young engineer was very reluctant to acquire a label as a specialist early in his life, such as "bridge engineer". He was content to have it for 2 years and then to pass on to something else, for fear of being accused of being a specialist of limited experience. Mr Whitehead thought, therefore, that the full experience of practical work as at present laid down could be modified to include some traffic engineering experience, but it should not be changed so that traffic engineering experience was a qualification in itself.

55. The fourth question seemed to be a matter for the Council of the Institution and for the existing Board. It should be referred to the Road Division Board in the first place, and he felt strongly that the Board should co-opt some experts who were not civil engineers by profession or in the actual work which they did, because they could contribute something very useful in reporting to the Council on how the problem could be dealt with.

Mr J. T. Duff (Senior Engineer, Ministry of Transport and Civil Aviation) also believed that some special organization by the Institution was required. Some place should be found in the Institution's examinations for traffic engineering. Until the Institution required some knowledge of traffic engineering, it seemed unlikely that universities and colleges would attempt to give instruction in the subject, because students would be reluctant to spend time in acquiring knowledge of traffic engineering which could not be put to use in the examination. When they had graduated and gone out into the field, some of the time spent in getting traffic engineering experience should help to qualify them for associate membership; otherwise they would be reluctant to spend any time at all in traffic engineering units, which he hoped that more and more authorities would eventually set up.

57. The problem of the admission of non-members had perhaps been overemphasized. There was a limited number of people at present who were not engineers but who had had considerable experience in traffic engineering. If this problem were handled correctly in future, however, and if young engineers trained as highway engineers were given some experience of traffic engineering, it seemed probable that in future almost all those who were interested in traffic engineering would be members of the Institution, and there would be no problem.

58. To encourage traffic engineering, some special body should be formed of a very temporary nature to start things on the right lines, and non-members of the Institution should be on that body in order to advise on the best methods of fostering the development. 
Dr T. E. H. Williams (King's College, University of Durham) also replied affirmatively to the first question. Dealing with the second, he said that it must be recognized that traffic engineering was based on factual studies by practitioners and research workers of the characteristics of the complex problems posed by drivers, vehicles, pedestrians, and roads. Those who made these studies included many people who were not members of the Institution, and he felt that they should be encouraged to attend the meetings when any facet of traffic studies or traffic engineering was discussed.

60. He proposed to concentrate on the third question, because he was particularly interested in the place of traffic engineering in the Institution in so far as it affected the development of the subject in universities. It had been gratifying to read in the notice of the present meeting that there was a growing feeling that the younger highway engineers should receive more training, both in universities and in colleges of advanced technology, in the subject of traffic engineering. In the light of his own experience, having had discussions on the subject with members of many local associations of the Institution of Civil Engineers and other bodies, he would say that that opinion was widely held at all levels, from the top executive to the junior engineer.

61. The universities and colleges of advanced technology were the obvious centres for instruction in the basic principles of traffic engineering. This should be accomplished by means of normal courses at undergraduate and postgraduate levels and by special intensive short courses for engineers in the field. These courses should be planned to meet the needs of three groups of students: (i) civil engineers with a general knowledge of highway and traffic engineering; (ii) civil engineers with a special knowledge of traffic engineering, or "traffic engineers" and (iii) potential research specialists in traffic engineering. Through these courses, the universities and colleges of advanced technology would form the essential link between the research worker and the practitioner.

62. The repeated successes of short courses in traffic engineering which had been organized by local associations of the Institution and the Institution of Municipal Engineers, the Road Research Laboratory, and various universities was clear evidence of the degree of interest in the subject and of the need for such courses. In the future, there would be a continued need for short courses in traffic engineering to enable practitioners to keep in touch with new developments in this dynamic field.

63. In universities which offered courses of study in traffic engineering at undergraduate and postgraduate levels there was a growing interest amongst students in the subject. The dynamic problems associated with traffic engineering had been proved to present an intellectual challenge to students. Its inclusion with other subjects in the curriculum had stimulated and revitalized highway engineering as an academic subject. If this interest was to be maintained, it was essential that young graduates should have the opportunity of a period of practical training in traffic engineering and that such training should be recognized by the Institution as qualifying them for corporate membership. It might be argued that all young graduates who were interested in traffic engineering should be prepared to undertake a period of practical training in general highway engineering to enable them to qualify for corporate membership, and then revert to their primary interest of traffic engineering. He would reply to that argument by giving certain factual information.

64. A postgraduate course in highway engineering and traffic studies had been available at King's College, Newcastle-upon-Tyne since 1954. A final (fourth) year option for undergraduates in the same subject had been available since 1957 . Including the students for the present academic year, ending June 1959, a total of 20 students had pursued this course of studies, including 12 from England and 8 from other countries in the Commonwealth. The majority of those students had shown a bias of interest towards the traffic engineering part of the course in preference to subjects concerned with road construction, including soil mechanics, properties of road materials, and pavement design. Of the 12 English students one was at present employed fulltime in traffic engineering; one had recently transferred from research in traffic engineering to research in road materials in order to qualify for corporate membership; two 
were with county highway departments, serving their 2 years under agreement; while two of the students who were at the present time engaged in their studies would probably join a local authority next July. Thus, over $50 \%$ of the number of English students who had taken this course had chosen branches of civil engineering other than highway engineering for their practical training. Had it been possible for this latter group of graduates to receive training in traffic engineering to qualify for corporate membership, every one of them would probably be engaged in highway engineering today.

65. The eight postgraduate students from overseas had been engaged in highway engineering prior to being awarded the scholarships which had enabled them to come to Britain, and in all cases they had returned to their previous posts, or would do so.

66. It was of interest to note the results of a survey carried out in the United States during the academic year 1957-58. This survey5, which had covered 18 universities, showed that a total of 256 postgraduate students in highway engineering included 156 $(61 \%)$ with the major parts of their programmes of studies consisting of courses in traffic engineering and highway planning. The remainder $(39 \%)$ had programmes with a bias towards highway materials. The report on this survey did not say whether or not those students were engaged or would be engaged in highway engineering, but he had had experience as a post-doctoral student in 1955 in the Institute of Transportation and Traffic Engineering of the University of California at Berkeley, and as visiting professor in 1957-58 at Northwestern University in Illinois, where he had taught postgraduate courses in highway and traffic engineering, and in his experience all the students with traffic "majors" would either be practising highway and traffic engineers or be full-time students who were potential highway engineers.

67. The success or failure of any course of studies was controlled by the number and quality of the publications available on the relevant subjects. In past years, with the exception of a few valuable contributions from practising engineers, those in Britain had been mainly dependent on the staff of the Traffic and Safety Division of the Road Research Laboratory for publications in traffic engineering. The high standard of those research publications was recognized internationally and they formed an essential core of invaluable references. In the field of traffic engineering practice there was a lack of publications on methods used by British engineers for the control of traffic movements and basic traffic statistics on volumes, speeds, delays, accidents, road and intersection capacities, and pedestrian characteristics. Fortunately, there was available a considerable number of references on traffic engineering practice from the Transactions and Proceedings of the American Society of Civil Engineers, the Institute of Traffic Engineers and the Highway Research Board, and also French and German publications.

68. More publications on traffic engineering practice in Britain should be encouraged. The formation of a traffic engineering division within the Institution would have a stimulating effect in that direction, in addition to providing a forum for discussion. In the light of American experience, it was highly probable that such a division would be a very dynamic and flourishing one.

Mr David Watson (County Surveyor, Warwickshire) said that he was largely in agreement with Sir Herbert Manzoni's remarks. If the Institution did not address itself to the problem, some other body would, with all the dangers of the formation of other splinter groups, which he very much deplored.

70. In his own office for very many years he had regarded his senior assistants as being people who, in the ordinary course of their work, had been able to pick up sufficient of the basic elements of traffic engineering to do the job quite well in collaboration with their counterparts in the Ministry of Transport. It was a pity that so much of their energy and effort in the past 12 years had been devoted to providing the arguments which would persuade the necessary money out of a reluctant Treasury for the work which should have been done long ago.

71. That, however, was not enough. It was necessary to tackle the problem by adopting a much more positive approach. As Dr Williams had said, the universities and 
colleges could do a great deal in this field. Mr Watson wished that there were more day and evening classes in the provincial universities and colleges to which engineers could be seconded to keep them fully abreast of the developments.

72. In that regard, he was very much attracted by the suggestion made by Mr Rawlinson for a separate diploma. There was a great deal to recommend that idea. It must be kept in mind that what was involved was essentially an engineering problem.

73. With regard to the second question, relating to people who were not chartered civil engineers, he realized quite well that at the present stage there were many people who had very much to offer, and he hoped that the committee envisaged in the fourth question would get down to the problem of how best to bring them in.

Mr G. H. Armitage (Traffic Officer, City Engineer's Dept., Newcastle-upon-Tyne) referred first to the question of admitting non-members and the setting up of a committee which would include them. In the subjects under the heading of public works, one of two things normally happened: either some general code of practice was drawn up by the professional institution, or a committee was appointed by the Government department concerned whose report served that purpose. Traffic engineering was developing far too rapidly for any general guidance of that kind to be produced at the moment, but he suggested that the Institution could do a very valuable job by convening a reviewing committee. This should include a certain number of non-members, particularly scientists and police officials, and perhaps through a publication of the Géotechnique type, could issue periodical reviews and recommendations.

75. Secondly, with regard to practical training, a short experience of operating a traffic-engineering section in a city engineer's department, indicated that the only way to get assistants was to train them on the job. In Newcastle-upon-Tyne, where he worked, traffic and highway engineers were receiving a year's special training at King's College, but were not subsequently available for traffic work with highway authorities because of the present requirements for qualification for associate membership of the Institution. He would like to suggest that practical engineering experience in the field in traffic engineering should at least be accepted as a part of the necessary experienco.

Mr Peter Sutcliffe (Lecturer in Civil Engineering, Leeds University), thought that the subject of traffic engineering had an exceedingly wide coverage in terms of the field of study and activities. There was a large number of disciplines and professions other than civil engineering proper, and in fact other than engineering at all, which were implicated in some way or other in its effective pursuance. Apart from mathematicians (with an emphasis on statistics), town planners, and others with whom civil engineers were accustomed to work closely, it was not fantastic to bring in also the economists, the lawyers (traffic control involved legal methods), sociologists, and the medical profession in some of its aspects, because traffic behaviour was to some considerable extent influenced by human beings. Engineers in other specialist fields were also implicated.

77. He suggested that, with all those professions and disciplines being involved, there was a need for some common meeting ground, some type of forum where the various experts could get together to discuss their common problems.

78. To emphasize the question of wide interests and diverse nature a little more, there was a statement in one of the American publications on traffic engineering to the effect that there was no area of public work which involved so many agencies and interests of state and municipal government as traffic. In one way or another, almost all the key departments of the Government had a responsibility and interest in traffic matters. Because traffic was so intimately related to economic and social values, it was inevitable that work in the highway traffic sphere touched on and influenced a wide diversity of interests and views. That was written of America, but it applied to any country with traffic in the modern sense.

79. That was one aspect of the problem, and resulted in the need for a committee, association, or conference to provide a platform for the exchange of views and information and for the co-ordination of effort. But the central figure in the whole activity 
remained the traffic engineer, and it was desirable to be careful not to overemphasize traffic by underemphasizing the engineer. The man, he suggested, was first and foremost an engineer, a man who was trained in what might almost be called scientific prediction and who was able to appreciate a situation, to formulate plans and to see whether or not something would work before it was built.

80. That brought out the second main aspect of the problem, the acceptance of traffic engineering as a part of civil engineering. The award of a professional qualification to traffic engineers, subject to the completion of a satisfactory training, was important. He would emphasize what had been said by other speakers. In at least one other country there was an independent Institute of Traffic Engineers; the creation of such a separate body was not basically in every respect a good thing.

81. He believed that universities were ideal centres for the study of traffic engineering. They exhibited a wide diversity of disciplines and professions; and research, which played so large a part in university life, was also an essential process in traffic engineering. Many problems in traffic engineering were in themselves research projects. Further, the universities possessed both the specialist staff and in many instances the equipment, such as computers, to deal with the various problems involved.

82. Turning to the specific problems which had been raised, to some extent the first and second questions had to be answered together. It had occurred to him that, in terms of fostering traffic engineering, one might think of the possibility of setting up some form of joint organization representing all the interested professions and disciplines, as had been done in other fields; the British Nuclear Energy Conference was an example. In such a body the Institution should play a reasonably leading part, and in the allocation of seats might have a major holding. He questioned whether it was really necessary for there to be any new special provision by the Institution for dealing with those aspects of traffic engineering which were domestic to the Institution. Could not the Road Division be given the trusteeship of such matters, being perhaps re-named the Highway Division? Highway engineering consisted of two wings: on the one hand road construction engineering, from the surface downwards, and on the other traffic engineering studies, from the surface upwards. The two went together.

83. On the question of whether the practical training of traffic engineers should include a period on works construction he felt that it should embrace some experience of this kind, for the reason which he had already mentioned, that the traffic engineer was basically an engineer, and an engineer should have site experience. He must be able to appreciate the effects of some of his traffic engineering decisions on the constructional processes, but the period "on site" might conceivably be reduced from that normally required. Practical training in traffic engineering would make demands on the time of the trainee, in that there would be much field observational work to undertake, and these two aspects would have to be balanced.

84. Mr Sutcliffe felt that he had answered the fourth question by his earlier remarks. Something like a special committee would be needed, either a re-organization within the Road Division or a wider Board or Joint Conference or Committee.

Dr G. Charlesworth (Head of Traffic Section, Road Research Laboratory) thanked the Institution for allowing him, as a non-member, to take part in the discussion and air his prejudices. He was broadly in sympathy with what Mr Andren, Dr Smeed, and Dr Williams had said.

86. His affirmative answer to the first question was based on a consideration of the present state of traffic engineering in Britain. There were three aspects of the subject: research, practice, and training. A great deal of traffic engineering would have to be done by civil engineers, and in his view the state of traffic engineering practice was inadequate at the present time. The Institution ought to do something about that. Training also needed looking into. It did not seem that the courses offered in Universities and similar institutions were properly taken up, and yet the attendance at the short courses offered by the Road Research Laboratory had increased during the past year 
by about $50 \%$, from 105 to 150 . It looked as though the short course was more attractive.

87. On the second question, members who had spoken had done so, quite properly, from the point of view of the Institution, and asked "Should we let these other specialists into our Institution?" Dr Charlesworth was on the other side of the fence, and he had to consider whether or not he wanted to be associated with the Institution. As a non-member of the Institution of Civil Engineers, he would like to take part in discussions on traffic engineering but he did not think that the field of traffic engineering was by any means the sole province of the civil engineer. The physicist, the mathematician, and the economist had a great contribution to make to the subject.

88. On the third question, something ought to be done, he felt, about allowing traffic engineering to count for practical experience, because the present situation was hampering the growth of traffic engineering. Reference had been made to specialization in highway departments. The question of specialization also arose in research departments, and an effort was made to move the junior officers around so that they obtained as wide an experience as possible. There were difficulties, but he suggested that the chief officer in a highway department might well do the same, to get over the difficulty of over-specialization.

Mr J. L. Paisley (Ministry of Transport and Civil Aviation) pointed out that $75 \%$ of those entering the Institution at the present time obtained exemption from the Institution examinations by the fact of having a degree, so that the question of courses was primarily one for the universities rather than for the minority who took Parts 1 and 2 .

90. On the third question, highway engineering was a branch of civil engineering and to that extent represented an element of specialization. Traffic engineering was a subdivision of highway engineering and a second degree of specialization. Those accepted as associate members of the Institution were accepted as having fulfilled the first requirement as qualified civil engineers, and he would submit that that requirement was adequately satisfied only if they had completed reasonably the basic discipline for a civil engineer, which in his submission required that they should have had experience on works and had rounded off at this level the theoretical training which for the bulk of them had come through a university course.

Mr O. A. Karensky (Partner, Messrs Freeman, Fox \& Partners, Consulting Engineers) welcomed very warmly the Council's proposal that traffic engineering should be dealt with by the Institution. As others had said, if the Institution did not do it some other body would.

92. To the first and second questions he would answer that the Institution should form a body which would deal with traffic engineering, but in his view it should be done on the lines on which soil mechanics had been dealt with, by a special section of members of the Institution with free access to all other members of the engineering and scientific community who were interested in the subject, without their necessarily becoming members of the Institution. There should be a forum in which scientists, economists, and engineers could exchange ideas on the subject without necessarily being qualified members of the Institution.

93. Turning to the third question, he was not in favour of the Institution giving any diplomas whatever to anybody. He did not think that it was the function of the Institution to give diplomas, and he did not think that the standard of the Institution should ever be lowered from what it was today. Diplomas, he suggested, should be given by the universities and by the Road Research Laboratory to students or practising engineers who had been through a special course or had special qualifications.

94. On the other hand, he would welcome permission to count as practical experience some part of the work on traffic engineering. Talking in terms of figures, perhaps 6 months of practical experience in traffic engineering could be counted. All the other qualifications would be required. 
95. That brought him to the last point, whether or not a special committee should be set up. He thought that the answer to that was "yes", because if the problem was dealt with on the soil mechanies principle it would require a special committee to be set up by the Council, possibly with co-opted members from the Road Research Laboratory and others highly versed in the subject, to start the ball rolling. He did not think that this subject should necessarily come under the Road Division.

Mr G. J. Roth (lately Rees Jeffreys Fellow at the Road Research Laboratory) said that traditionally traffic engineering was part of civil engineering. Telford, who had been one of the founders of the Institution, had spent a good deal of time in deciding whether roads or canals should be built to connect various centres of population. That was an example of selecting the best route and the best kind of transport medium to do a job. It was well known how Brunel had had to fight for the Great Western Railway and justify his route by engineering and economic arguments. That was the kind of thing that the traffic engineer had to do to-day.

97. The important thing for the Institution to consider was the method of traffic engineering. Engineering, as he understood it, involved trying to do a given job in the most economic and simple way. That was the basis of engineering design. A traffic engineer had to do the same thing and to use the same approach; his job was to design the most suitable framework of roads or railways to carry a given volume of traffic. It was unfair to say that counting traffic was not really civil engineering; it might as well be said that measuring rainfall was not really civil engineering, but that was work that had to be done in the design of any drainage or hydro-electric scheme. Every job had its ancillary works, which together went to make up the whole.

98. He suggested, therefore, that traffic engineering had already been considered by the Institution to be a part of civil engineering, and that it was misleading to suggest that it was something new which had been suddenly sprung on it.

99. His answers to the four questions were very similar to those of Mr Kerensky. He would only add to those answers that it would be very useful to a traffic engineer to have had some experience of either road construction or research into road materials.

Mr R. E. D. Bain (Chief Engineer, Belfast City \& District Water Commissioners) prefaced his remarks by mentioning that he was not a road engineer, but at a recent meeting of the Committee of the Northern Ireland Association this subject had come up for discussion, and therefore some of the views which he would express would be that Association's views rather than his own.

101. Endorsing Mr Watson's remarks, Mr Bain said that he and his colleagues in Northern Ireland felt strongly about splinter groups. In their comparatively small area they had quite a number of branches of different institutions, and it was extremely difficult to get a large attendance at meetings of those splinter groups. They felt that the Institution as a whole would be greatly strengthened if it were possible to bring back some of the lost fraternity. They viewed with concern, therefore, any suggestion which might lead to the formation of yet another group, and thought that the answers to the questions which had been put should be given with that in mind, that anything which was done should be done by the Institution and that they should try to encourage the traffic engineers to come to the Institution by offering them better facilities than they could provide for themselves, so that they would be attracted into the Institution rather than branch off to form an organization of their own.

102. In answer to the first question, therefore, they believed that special provision should be made by the Institution. It would be preferable to do it by an extension of the present Road Division, but, if that was insufficient, the Institution should form another division, or something similar.

103. The answer to the second question was that the Institution should open its doors as widely as possible. He did not altogether agree with the attitude of Sir Herbert Manzoni in saying "no" to this question. Mr Bain thought that the Institution 
should open its doors but not lower its standards; it should try to find some means of bringing in new people.

104. He agreed with the general views on the third question and his answer to the fourth was that a separate committee should be established. The matter should not be left entirely to the Road Division, because those who ran the Road Division might have a bias in favour of their own point of view. It would be better to get a wider range of -opinion, and consideration should definitely be given to including non-members of the Institution on the Committee to discuss the whole matter.

Mr D. A. de C. Bellamy (formerly Senior Engineer, Ministry of Transport and Civil Aviation) said he had started his professional life about 40 years ago as a highway engineer. About 1928, traffic engineering had started in Britain and, as a highway engineer, he had taken a great interest in it. Later he had taken a post in an office staffed with real traffic engineers and he had rapidly found that there was an immense amount that he had to learn, and he had had to modify appreciably his approach to the subject. The point was that the highway engineer approached these problems in rather a different way from the traffic engineer, and so it was necessary to be both, because it was not possible to work with a specialist without understanding his approach.

106. On the question of works training, a man who had not done works was not a complete engineer, nor indeed was he an engineer at all. It was the only way in which to study men and get to know them, to get to know the mentality of the foremen and the workmen and of one's brother engineers. Works training was essential for the fully qualified engineer.

The President briefly summarized the discussion in relation to the four questions which had been put.

108. On the first question - whether or not any special provision by the Institution was needed-he thought that if the word "special", which had little significance, were omitted, opinion was unanimous that it was the function and the duty of the Institution to provide for the branch of highway engineering which had been discussed.

109. On the second question - the extent to which it was advisable to bring in nonmembers - the consensus seemed to be that it was desirable, but there appeared to be some degree of misunderstanding about the meaning of "participation". It did not mean that members of this new profession (if one liked to call it so) were necessarily civil engineers and should become corporate members of the Institution, but that they should be brought in in the same way as scientists who now took part in the work of the soils group. There seemed to be a general impression that the Institution ought to open its doors as widely as possible but with no lowering of standards, and one speaker suggested that if the committee envisaged in question (iv) were appointed its first duty might be to advise the Council on the conditions under which this should be done.

110. On the third question the President thought that opinion generally was that the traffic engineer should have a period of works experience, but one or two speakers seemed to have misunderstood the question and addressed themselves rather to the opposite one as to whether or not highway engineers should have a period of experience in traffic engineering.

111. On the fourth question, there seemed to be general agreement that the activities outlined should be run by an ad hoc committee. Many speakers thought that this would be a function of the Road Divisional Board, but others felt that a Committee perhaps consisting of the present Board together with other experts on traffic engineering would be better. The consensus seemed to be that specialist traffic engineers should be adequately represented.

Dr Glanville thanked the President for summarizing the discussion so admirably that there was little left to say. As the meeting progressed there seemed to be a growing feeling that the Institution should bring in more generously experts who were not members of the Institution, and he felt that any committee which was set up-and he 
was glad that the general view was that there should be such a body-to consider this matter should take that very seriously into account, and he was sure would do so.

113. He was very pleased that the meeting had come to the conclusion on question (i) that the Institution should take a much more active part in traffic engineering.

114. On the question of whether practical experience in traffic engineering should count as a part of practical training, the general feeling, which the President had not mentioned in his summing up, seemed to be that it should count in part. It was felt that at least a part of traffic engineering experience should count, and that was an important point, and would be of definite advantage to those who wished to specialize in traffic engineering.

115. Dr Glanville felt himself to be on the academic side, with Dr Charlesworth and others, and believed in opening the door to a wide number of people of different disciplines and discussing the problems with them. Engineers owed a great deal to these other disciplines and relied on them in many ways, and the more that they could learn from them by discussion the better their position would be.

\section{REFERENCES}

1. J. H. Jones, "Selected aspects of the geometrical design of airports". Proc. Instn civ. Engrs, pt. II, vol. 5, p. 1 (Feb. 1956).

2. J. F. Bickerton and P. Protopapadakis, "Notes on the design and layout of large passenger stations". Railway Paper No. 20. Instn civ. Engrs, 1946.

3. F. S. P. Turner, "Preliminary planning for a new tube railway across London". Proc. Instn civ. Engrs, vol. 12, p. 19 (Jan. 1959).

4. M. J. Lighthill and G. Whitham, "On kinematic waves. II. A theory of traffic flow on long crowded roads". Proc. roy. Soc., Series A (1955), p. 317.

5. D. S. Berry, "Training traffic engineers". Int. Road Fedn, 3rd World Mtg Rep., 1958. 